\title{
Preclinical Study of Novel Curcumin Analogue SSC-5 Using Orthotopic Tumor Xenograft Model for Esophageal Squamous Cell Carcinoma
}

\author{
Lai Nar Tung, BSc, MPhill,2 \\ Senchuan Song, BSC, PhD 3,4 \\ Kin Tak Chan, BSc, MPhil, PhD ${ }^{1}$ \\ Mei Yuk Choi, BSc, MPhil ${ }^{1}$ \\ Ho Yu Lam, BSc ${ }^{1}$ \\ Chung Man Chan, BSc, MPhil, $\mathrm{PhD}^{1,2}$ \\ Zhiyong Chen, BSc, PhD ${ }^{4}$ \\ Hector K. Wang, BEng, MPhil ${ }^{1}$ \\ Hoi Ting Leung, $\mathrm{BSC}^{1}$ \\ Simon Law, MBBChir, MS, PhD, FRCSEd, \\ FCSHK, FHKAM ${ }^{1}$ \\ Yanmin Huang, BSc, $\mathrm{PhD}^{5}$ \\ Huacan Song, BSc, $\mathrm{PhD}^{3}$ \\ Nikki P. Lee, $B S c, P h D^{1,2}$
}

*A list author's affiliations appears at the end of the paper.
Correspondence: Nikki P. Lee, BSc, PhD Department of Surgery, The University of Hong Kong, Faculty of Medicine Building, 21 Sassoon Road, Pokfulam, Hong Kong Tel: 852-3917-9652

Fax: 852-3917-9634

E-mail: nikkilee@hku.hk

Co-correspondence: Huacan Song, BSc, PhD School of Chemical Engineering and Technology, Sun Yat-Sen University, Guangzhou 519082, China

Tel: 86-20-8411-0918

Fax: 86-20-8411-2245

E-mail: yjhxhc@mail.sysu.edu.cn

Received July 25, 2017

Accepted January 16, 2018

Published Online January 24, 2018

* Lai Nar Tung and Senchuan Song contributed equally to this work.

\section{Purpose}

Tumor xenograft model is an indispensable animal cancer model. In esophageal squamous cell carcinoma (ESCC) research, orthotopic tumor xenograft model establishes tumor xenograft in the animal esophagus, which allows the study of tumorigenesis in its native microenvironment.

\section{Materials and Methods}

In this study, we described two simple and reproducible methods to develop tumor xenograft at the cervical or the abdominal esophagus in nude mice by direct injection of ESCC cells in the esophageal wall.

\section{Results}

In comparing these two methods, the cervical one presented with more clinically relevant features, i.e., esophageal stricture, body weight loss and poor survival. In addition, the derived tumor xenografts accompanied a rapid growth rate and a high tendency to invade into the surrounding structures. This model was subsequently used to study the anti-tumor effect of curcumin, which is known for its potential therapeutic effects in various diseases including cancers, and its analogue SSC-5. SSC- 5 was selected among the eight newly synthesized curcumin analogues based on its superior anti-tumor effect demonstrated in an MTT cell proliferation assay and its effects on apoptosis induction and cell cycle arrest in cultured ESCC cells. Treatment of orthotopic tumor-bearing mice with SSC-5 resulted in an inhibition in tumor growth and invasion.

\section{Conclusion}

Taken together, we have established a clinically relevant orthotopic tumor xenograft model that can serve as a preclinical tool for screening new anti-tumor compounds, e.g., SSC-5, in ESCC.
Key words

Curcumin, Esophageal squamous cell carcinoma 


\section{Introduction}

Esophageal cancer is one of the most life-threatening gastrointestinal cancers. It is composed of two main histological types, i.e., esophageal squamous cell carcinoma (ESCC) and esophageal adenocarcinoma. ESCC is commonly found in high risk Asian regions. It is originated from epithelial cells lining along the esophagus, and occurs frequently in the upper and middle parts of the esophagus. Patients may experience difficulty in swallowing and body weight loss due to the growing tumor that obstructs the esophageal lumen. The prognosis of patients is poor and approximately $10 \%$ of patients can survive for more than 5 years. Patients are strategically managed with multimodality treatments, including surgery, chemotherapy and/or radiotherapy. Despite that, there is no significant improvement on patient outcomes and that ESCC remains an aggressive cancer with high mortality. To address these clinical limitations, much efforts have been devoted to research for new treatments, especially for some new compounds with anti-tumor effects in ESCC.

Cancer research depends on the use of relevant animal models to provide a vital platform for preclinical studies. The most commonly used animal model for ESCC is subcutaneous tumor xenograft model, for which this model can be established by transplanting human ESCC cells / xenografts subcutaneously into immunodeficiency animals. This model is simple to establish and reproducible. However, it does not fully mimic the clinical situation as the tumor xenograft does not grow at the organ of origin, i.e., at the esophagus. Alternatively, orthotopic tumor xenograft model can be established by developing tumor xenograft at the esophagus, thus allowing the study of tumor-stromal interaction. As this interaction is important for tumorigenesis and responses to treatments [1-3], this latter model is more superior than the subcutaneous model when it is used to examine the antitumor effects of new compounds. A number of studies reported the successful establishment of ESCC xenograft in the animal esophagus either at the cervical or at the abdominal part [4-9]. Despite that, no studies have been conducted so far to compare different features of these two methods. This study addressed this issue and aimed to identify which of these two methods could be used to develop tumor xenograft model that can mimic the clinical ESCC situation better.

Curcumin, which is derived from Curcuma longa, has long been used in traditional medicine [10]. It is traditionally used to treat various disorders and diseases including cancers [11]. Its use in cancers is based on its anti-tumor effects on growth and apoptosis [12]. These effects can be mediated by different mechanisms, including transcription factor inhibition, cal- cium homeostasis disruption, and epigenetics modulation [13-15]. Despite these diverse anti-tumor effects, the clinical use of curcumin remains limited partly due to its poorly characterized pharmacokinetics profile and low potency [16]. In order to potentiate the clinical use of curcumin, several research groups synthesized different curcumin analogues by molecular structure modifications, e.g., PGV-0/PGV-1 and EF31/UBS109 with respective anti-tumor effects in breast and pancreatic cancers [16,17]. Despite these promising results, the study of curcumin in ESCC is limited and no studies have yet been performed on the use of curcumin analogues. To advance curcumin research in ESCC, this study employed the use of a clinically relevant animal model to examine the anti-tumor effects of a newly synthesized curcumin analogue SSC-5 in ESCC.

\section{Materials and Methods}

\section{ESCC cell lines}

In-house developed ESCC cell lines SLMT-1, HKESC-1, and HKESC-2 were used as before $[18,19]$. ESCC cell lines KYSE-150, KYSE-180, KYSE-270, KYSE-410, and KYSE-450 purchased from Leibniz Institute DSMZ-German Collection of Microorganisms and Cell Cultures (Braunschweig, Germany) were cultured accordingly. Cultured cells were maintained in a humidified atmosphere at $37^{\circ} \mathrm{C}$ with $5 \% \mathrm{CO}_{2}$. Culture reagents were obtained from Life Technologies (Waltham, MA).

\section{Nude mice}

Male nude mice obtained from Laboratory Animal Unit in The University of Hong Kong, Hong Kong were housed in individually ventilated cages under a 12-hour light/dark cycle, and fed with sterilized food and water.

\section{Orthotopic tumor xenograft models}

Two methods were used to establish tumor xenograft at the cervical and abdominal part of the esophagus in nude mice. In the first method to establish tumor xenograft at the cervical esophagus, a 10-mm incision was first introduced vertically and through the neck skin of an anesthetized mouse, which was prepared by intraperitoneal injection of sodium pentobarbital at $54 \mathrm{mg} / \mathrm{kg}$. Cervical muscles, salivary glands, and collective tissues between the trachea and the esophagus were carefully separated by fine point forceps, then the trachea was pulled lightly aside by serrated tip for- 

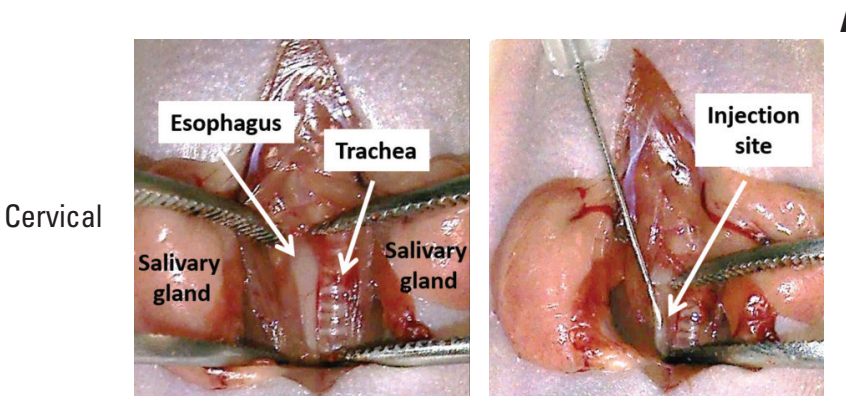

A
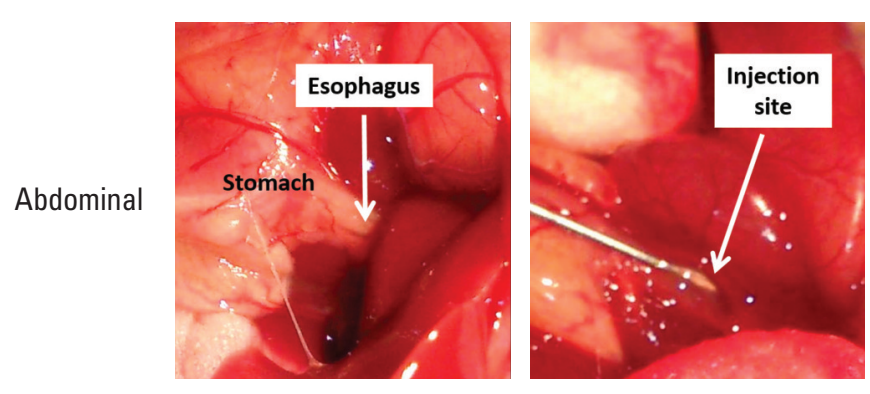

Fig. 1. Surgical procedures to inject esophageal squamous cell carcinoma (ESCC) cells at different anatomical locations in the mouse esophagus. ESCC cells mixed with Matrigel were injected into the esophageal wall at the cervical esophagus (A) and at the abdominal esophagus (B).

ceps to expose part of the cervical esophagus for cell injection. ESCC cells suspension in $20 \mu \mathrm{L}$ was injected into the esophageal wall using a 29-gauge BD Ultra-Fine insulin syringe (BD Biosciences, San Jose, CA) (Fig. 1A). A small edema at the cell injection site indicated successful cell injection. The cell suspension was prepared by mixing $1 \times 10^{6}$ ESCC cells in serum-free medium with an equal volume of Matrigel (Corning, Tewksbury, MA). After the surgical procedure, the skin was closed using non-absorbable 5-0 polypropylene suture (Ethicon, Somerville, NJ). In the second method to establish tumor xenograft at the abdominal part of the esophagus, a horizontal incision of $15 \mathrm{~mm}$ was made through the skin and muscle right below the rib cage of an anesthetized mouse using dissection scissors. After putting aside the liver and the stomach with serrated tip forceps, part of the abdominal esophagus between stomach and diaphragm was exposed for cell injection. ESCC cell suspension prepared above was then injected into the esophageal wall (Fig. 1B) and the appearance of small edema at the cell injection site indicated successful cell injection. For both methods, body weight and survival time of the mice were monitored after tumor cell injection. At the experimental end-point, the mice were sacrificed, while the tumor xenografts were dissected for size measurement. Serial cross-sections of the esophagus prepared from paraffin-embedded samples were stained with hematoxylin and eosin to detect any tumor invasion events into the esophageal lumen. These sections were also stained with Ki-67 and CD34 following a standard immunohistochemistry protocol. Histological images were viewed under a microscope and captured using a DXM1200F digital camera (Nikon, Tokyo, Japan).

\section{Curcumin analogues synthesis}

Curcumin was purchased from Aladdin (Shanghai, China). Curcumin analogues SSC-3, SSC-5, SSC-6, SSC-8, SSC-9, SSC10, SSC-19, and SSC-20 were designed and synthesized based on the reported methods [20-24], with some modifications. 1-Methylpiperidin-4-one (10.0 mmol) was added to the mixture of $24.0 \mathrm{mmol}$ of the corresponding aldehyde compound in $40-60 \mathrm{~mL}$ of saturated $\mathrm{HCl}-\mathrm{CH}_{3} \mathrm{CO}_{2} \mathrm{H}$ in a round bottom flask, which was then sealed and placed at $5^{\circ} \mathrm{C}-40^{\circ} \mathrm{C}$ for 32-72 hours. Ultrasonic oscillation was applied to promote the dissolution of aldehyde compound when necessary. The mixture was subsequently poured into $250 \mathrm{~mL}$ of ice water and stirred well before its neutralization with $25 \%$ of $\mathrm{NaOH}$ $\mathrm{H}_{2} \mathrm{O}$. Filtration was used to collect the solid product. The cake was grounded and washed twice with ethanol using ultrasonic oscillation. Further filtering and drying was used to obtain the pure product, which was then analyzed using 
the below instruments. WRS-1B digital melting point apparatus (Zhengzhou Nanbei Instrument Equipment, Henan, China) was used to measure the purity of substances. Varian Mercury Plus 300 spectrometer (Varian, Palo Alto, CA) (in DMSO- $d_{6}$ ) was used to obtain the NMR spectra. All chemical shifts $(\delta)$ were given in parts per million, while the coupling constants $(J)$ were given in hertz. Mass spectra were obtained from ZAB-HS (VG Analytical, London, UK), LCMS-2010A (Shimadzu, Kyoto, Japan) or LCQ Deca XP (Thermo Finnigan, Waltham, MA) mass spectrometers. Elemental analyses were performed in a vario EL/MICRO cube elemental analyzer (Elementar Analysensysteme $\mathrm{GmbH}$, Langenselbold, Germany) and results were generated within $\pm 0.4 \%$ of the theoretical values. Finally, curcumin and its analogues were dissolved in dimethyl sulfoxide (DMSO) (Sigma-Aldrich, St. Louis, MO) before use.

\section{MTT cell proliferation assay}

MTT cell proliferation assay was performed as described [18]. ESCC cells (2,000 to 8,000 cells / well) were seeded in a 96-well plate overnight before treatment with curcumin (1.25 to $20 \mu \mathrm{M})$ and its analogues $(0.625$ to $5 \mu \mathrm{M})$ for 48 hours. MTT reagent (Sigma-Aldrich) was added and incubated for an hour. The reduced MTT was dissolved in sodium dodecyl sulfate. Colorimetric signal was measured at $570 \mathrm{~nm}$, with $650 \mathrm{~nm}$ as a reference wavelength, in a Multiskan FC microplate reader (Thermo Fisher Scientific) and analyzed using Skanlt software ver. 3.1 (Thermo Fisher Scientific). Experiments were performed in triplicate wells, and repeated for three times.

\section{Cell cycle analysis}

Cell cycle was analyzed as before [25]. SLMT-1 and KYSE450 cells were treated with curcumin, SSC-5, and SSC-19 at $2 \mu \mathrm{M}$ (SLMT-1) or $1 \mu \mathrm{M}$ (KYSE-450). Treated cells were harvested at 16 to 24 hours afterwards and fixed with ethanol. After washing, the fixed cells were then re-suspended in $2 \mu \mathrm{g} / \mathrm{mL}$ propidium iodide (Sigma-Aldrich) and $200 \mu \mathrm{g} / \mathrm{mL}$ RNase (Life Technologies). Cell cycle was analyzed in a BD FACSCanto II analyzer (BD Biosciences) with the use of FlowJo software ver. 7.6.1 (FlowJo, Ashland, OR). Experiments were repeated in triplicate.

\section{Western blotting}

Protein lysates were prepared from ESCC cells treated with curcumin, SSC-5, and SSC-19 using RIPA buffer supplemented with complete EDTA-free protease inhibitors (Roche Applied Science, Mannheim, Germany) and PhosSTOP-phosphatase inhibitors (Roche Applied Science). West- ern blotting was conducted as before $[18,25]$ with the use of the following primary antibodies: mouse anti- $\beta$-actin $(1: 10,000$, Dako, Santa Clara, CA), rabbit anti-cleaved poly(ADP-ribose) polymerase (PARP; 1,5000, Abcam, Cambridge, MA), and rabbit anti-Bcl-2 (1:1,000, Abcam).

\section{In vivo tumor growth assay}

Tumor xenograft was developed at the cervical esophagus in mice using SLMT-1 and KYSE-450 cells as above. One week after tumor cell injection, mice were randomly divided into three groups (12 mice per group) and treated with an intraperitoneal injection of DMSO (control), $50 \mathrm{mg} / \mathrm{kg}$ curcumin and $50 \mathrm{mg} / \mathrm{kg}$ SSC- 5 three times a week for two weeks. At the end of the study period, tumor xenografts were collected for size measurement based on the use of the formula: tumor volume $=1 / 2\left(\right.$ length $\times$ width $\left.^{2}\right)$. The presence of tumor invasion into the esophageal lumen was assessed by histological examination as above.

\section{Statistical analyses}

Statistical analyses were performed using Excel 2007 (Microsoft, Redmond, WA) and Prism 6 ver. 6.07 (GraphPad Software, La Jolla, CA). Data in bar charts are presented as mean \pm standard deviation/standard error of mean. Student's $t$ test was used to calculate the difference between experimental groups. Post-treatment survival was analyzed by Kaplan-Meier method and log-rank test. A p-value of below 0.05 was considered statistically significant.

\section{Ethical statement}

Committee on the Use of Live Animals in Teaching and Research (CULATR) has approved the use of animals in this study.

\section{Results}

\section{Tumor xenograft establishment in mouse esophagus}

We successfully established tumor xenograft at the cervical or the abdominal part of mouse esophagus using SLMT-1 ESCC cells (Fig. 2A). Comparison of the two methods revealed shorter operation time for injecting tumor cells at the cervical esophagus ( $300 \pm 31$ seconds) compared to those performed at the abdominal part $(409 \pm 48$ seconds, $\mathrm{p}<0.01)$. Despite this difference, the percentage of mice survived after tumor cell injection was actually quite similar (cervical, 
A
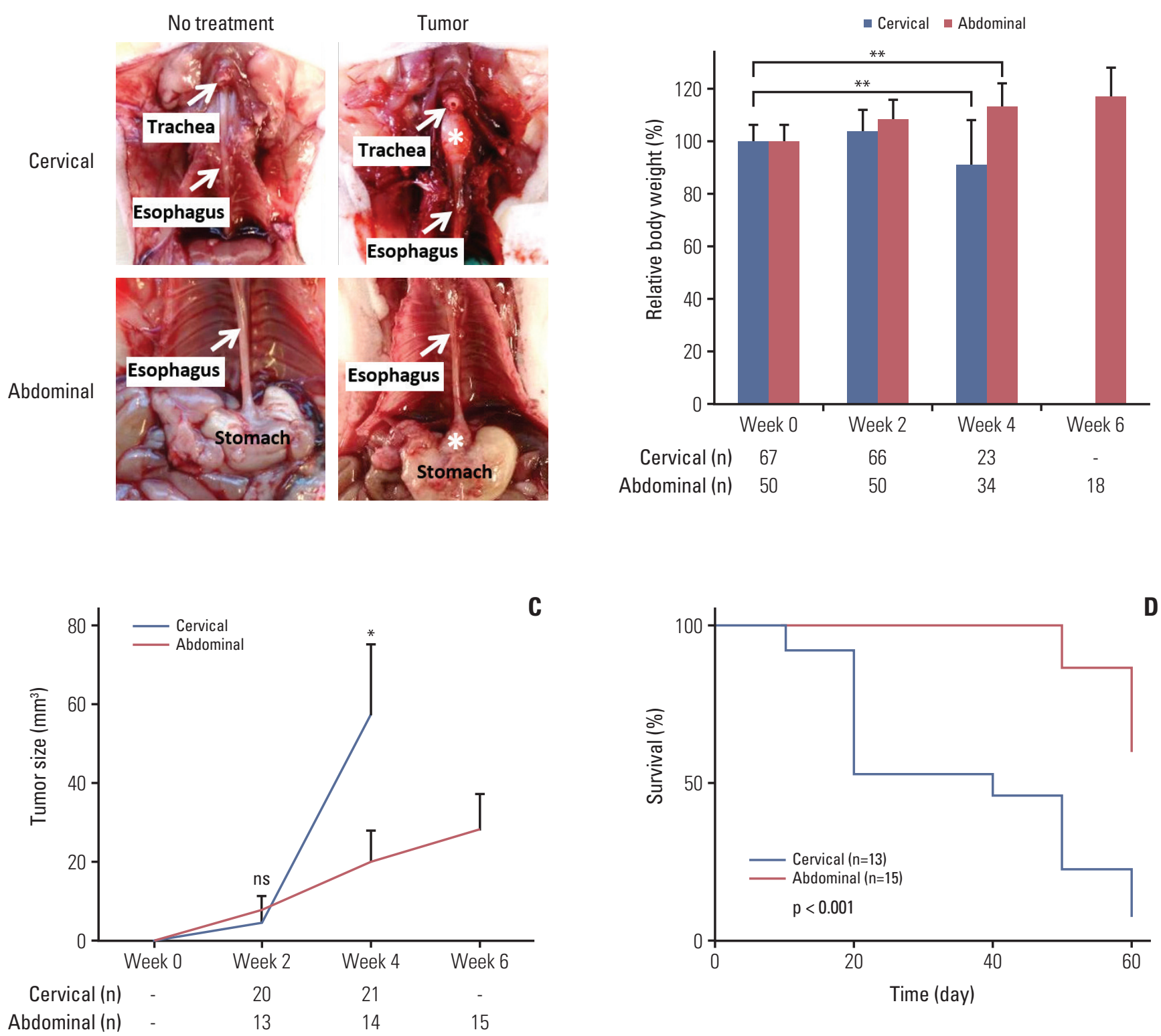

Fig. 2. Comparison between orthotopic tumor xenograft models at the cervical and abdominal esophagus. (A) Photos taken at week 4 (cervical) or week 6 (abdominal) after SLMT-1 esophageal squamous cell carcinoma cell injection into the esophageal wall show successful establishment of tumor xenografts, marked by asterisk, at the cervical or abdominal esophagus. (B) Mice bearing tumor xenograft at the cervical esophagus experienced a significant body weight reduction in 4 weeks' time, whereas a gradual increase was noticed in those with tumor xenograft at the abdominal esophagus. Bars indicate mean \pm standard deviation (SD). ${ }^{* *} \mathrm{p}<0.01$. (C) When the tumor xenografts were dissected for tumor size measurement every two weeks, we observed faster growth of tumor xenografts at the cervical esophagus compared to those at the abdominal esophagus. Error bars indicate SD. ${ }^{*} \mathrm{p}<0.05$. ns, statistically not significant. (D) Kaplan-Meier survival curve analysis revealed poorer survival in mice bearing tumor xenograft at the cervical esophagus than those with tumor xenograft at the abdominal esophagus. $\mathrm{p}<0.001$. $\mathrm{n}$, animal number. 
A

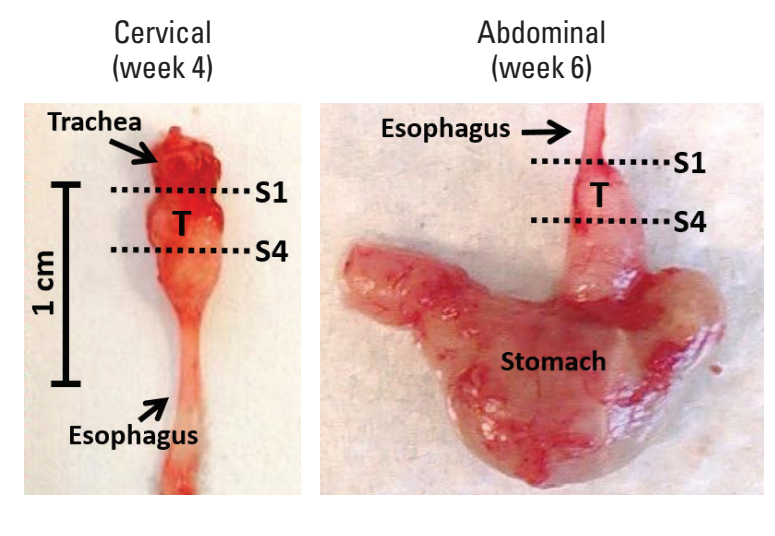

C

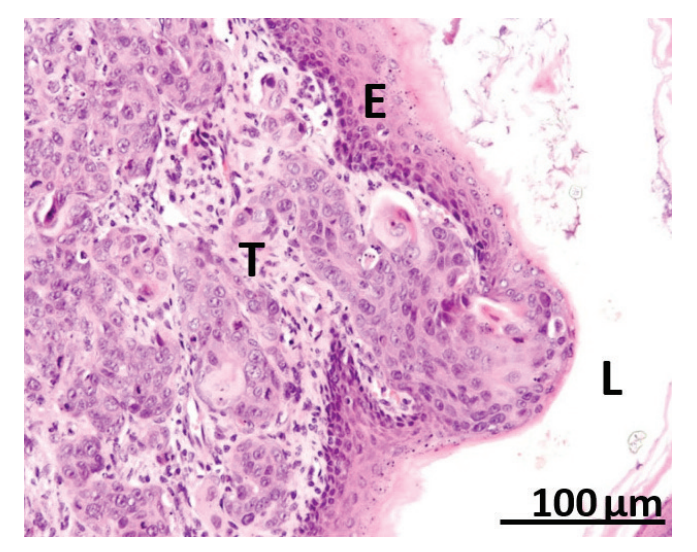

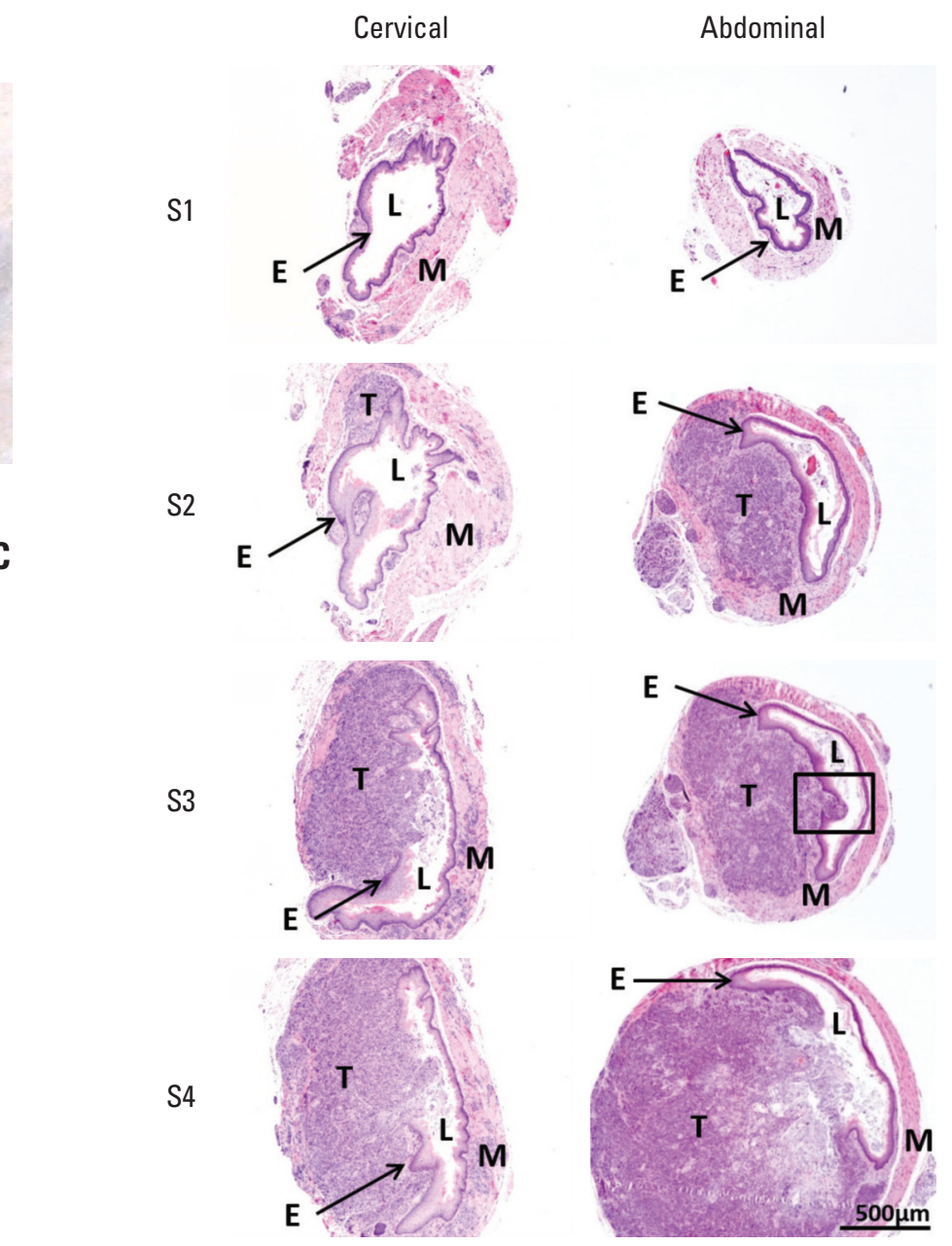

Fig. 3. Histological images of SLMT-1-derived tumor xenografts at the cervical and abdominal esophagus. (A) Mouse esophagus with tumor xenograft was dissected to prepare serial sections from proximal location S1 to distal location S4, as indicated by dotted lines. (B) Hematoxylin and eosin staining was used to reveal the histology of the representative sections at location S1, S2, S3, and S4. S1, no observable tumor; S2, tumor centered in the muscularis propria and submucosa of the esophageal wall; S3 and S4, tumor invasion into the esophageal lumen and at the same time causing luminal stricture $(\times 40)$. (C) The tumor invasive front can be clearly seen in a high magnification image of squared area in S3 section $(\times 200)$. E, epithelium of esophagus; L, esophageal lumen; M, muscular layer of esophagus; T, tumor.

93.06\%; abdominal, 92.59\%).

Next, we examined the effects of tumor xenograft growing at different parts of the esophagus on animal outcomes, i.e., body weight and survival. Mice with tumor xenograft at the cervical esophagus suffered significant body weight loss in four weeks' time after tumor cell injection $(\mathrm{p}=0.009)$, while the body weight of those with tumor xenograft at the abdominal part gradually increased up to 6 weeks (Fig. 2B). We first observed a faster growth rate of tumor xenograft at the cervical esophagus in 4 weeks' time compared to those at the abdominal part $\left(57.89 \pm 17.64 \mathrm{~mm}^{3}\right.$ vs. $20.43 \pm 7.71 \mathrm{~mm}^{3}$, $p<0.050$ ) (Fig. 2C). These effects observed in mice with tumor xenograft at the cervical esophagus could account for their shorter survival time after tumor cell injection (median, 40 days) compared to those with tumor xenograft at the abdominal part. In this latter animal group, as much as more than $50 \%$ of mice survived at the end of the study period on day 60 (p < 0.005) (Fig. 2D).

Tumor invasion into different layers of the esophageal wall is a hallmark feature of ESCC, for which this event can be readily visualized in our developed orthotopic tumor xenograft models. At different time points after injection of SLMT- 


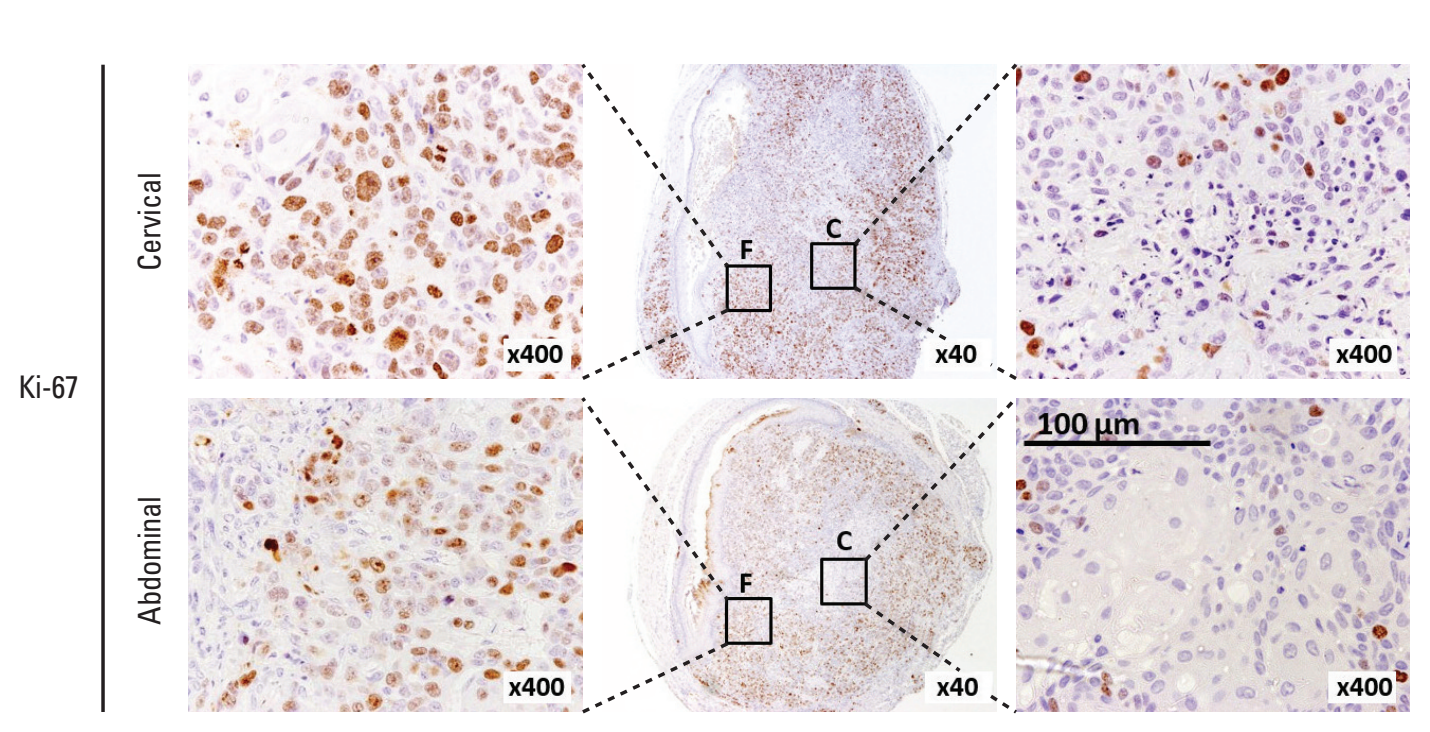

A

B

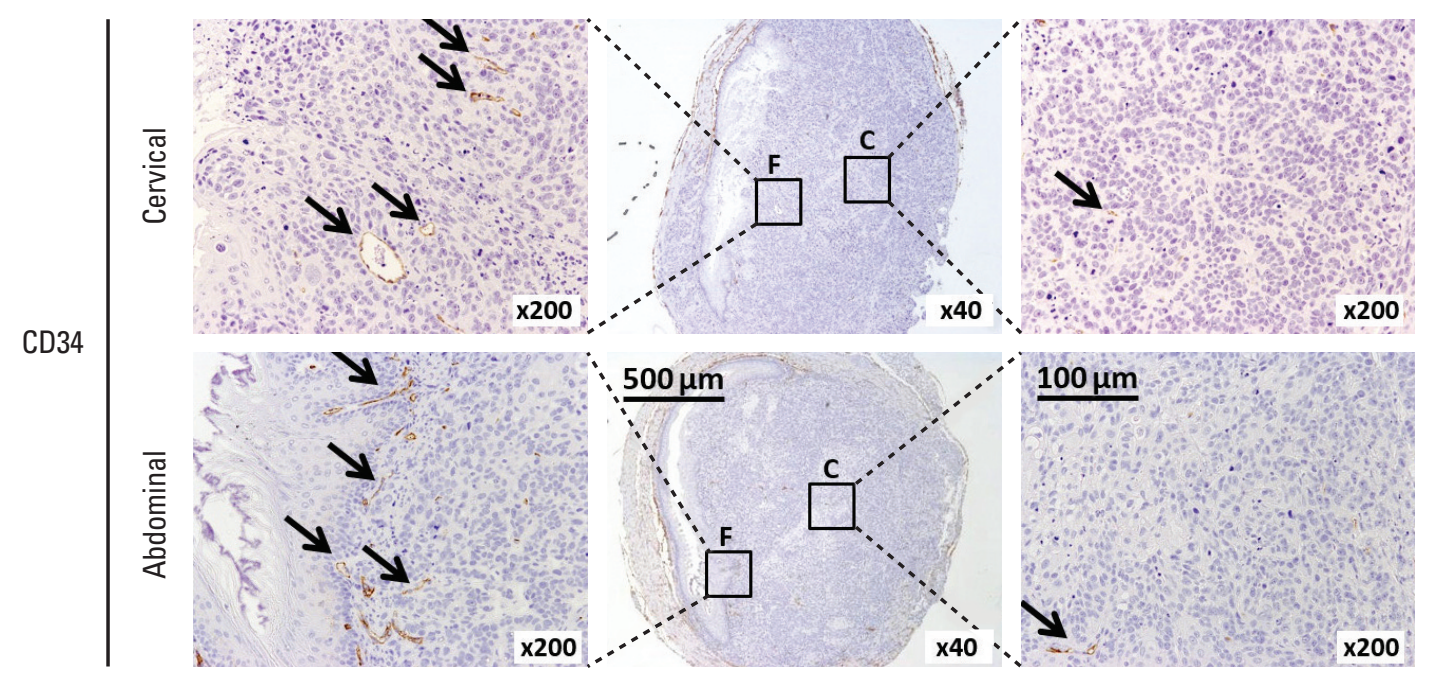

Fig. 4. Immunohistochemical staining of Ki-67 and CD34 in orthotopic tumor xenografts. Tumor xenografts formed at the cervical and abdominal esophagus using SLMT-1 esophageal squamous cell carcinoma cells were subjected to immunohistochemistry by staining with two different molecular markers, i.e., Ki-67 for proliferating cells (A) and CD34 for tumor vessels (B). Most of the positively stained cells (arrows) were concentrated at the tumor periphery (area F) rather than the tumor center (area C).

1 cells to form orthotopic tumor xenograft (cervical, week 4; abdominal, week 6) (Fig. 3A), we examined the serial cross sections of the esophagus and found that tumor xenograft centered in the muscularis propria and submucosa, and invaded into the lumen with ulceration of the squamous epithelium (Fig. 3B). In addition to lumen stricture (Fig. 3B), we also observed that the tumor invasive front broke through the squamous epithelium of the esophagus in a high magnification image (Fig. 3C). The growth of these tumor xenografts was supported by rapid cell proliferation and new blood vessel formation, as shown by the intense staining of two molecular markers at the tumor periphery, i.e., Ki-67 for proliferating cells (Fig. 4A) and CD34 for blood vessels (Fig. 4B). Collectively, these observations have clearly revealed the presence of tumor invasion in our models. 

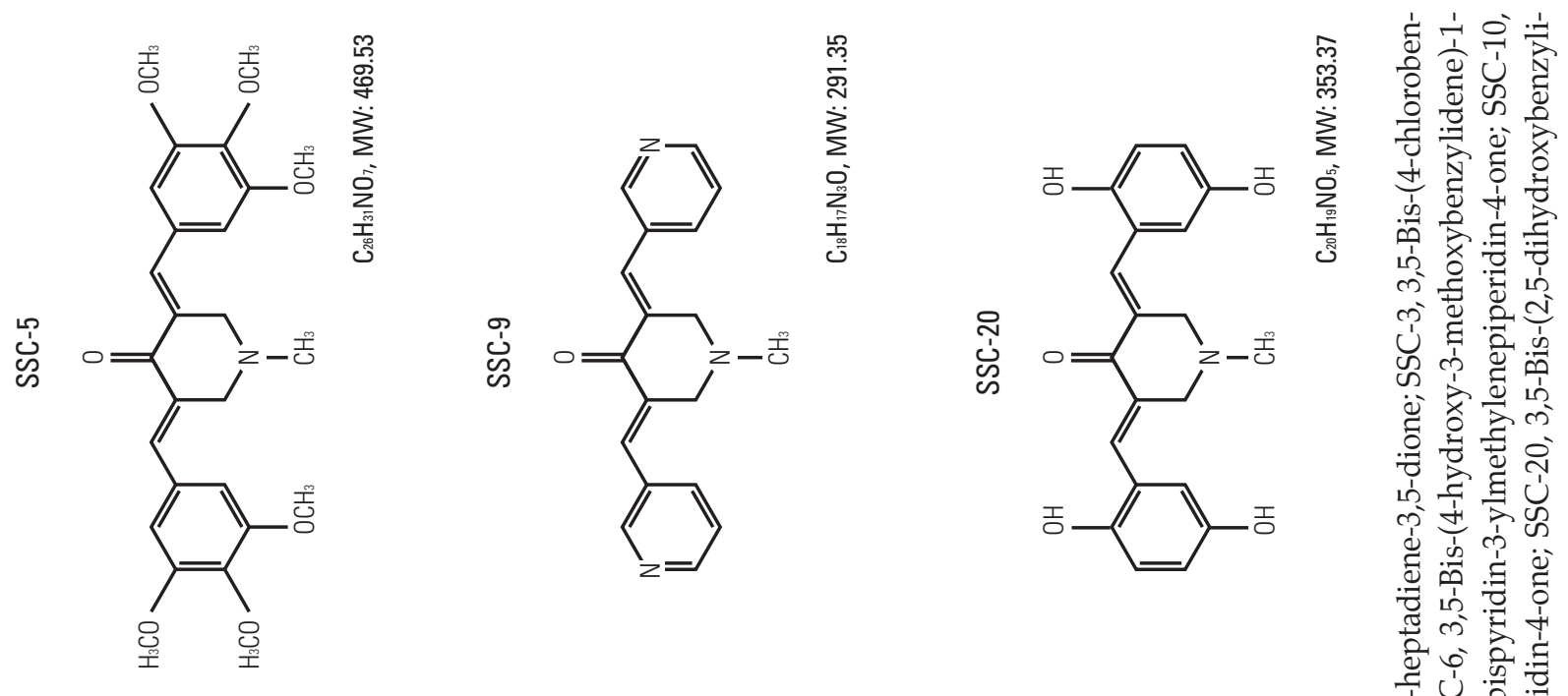

के की
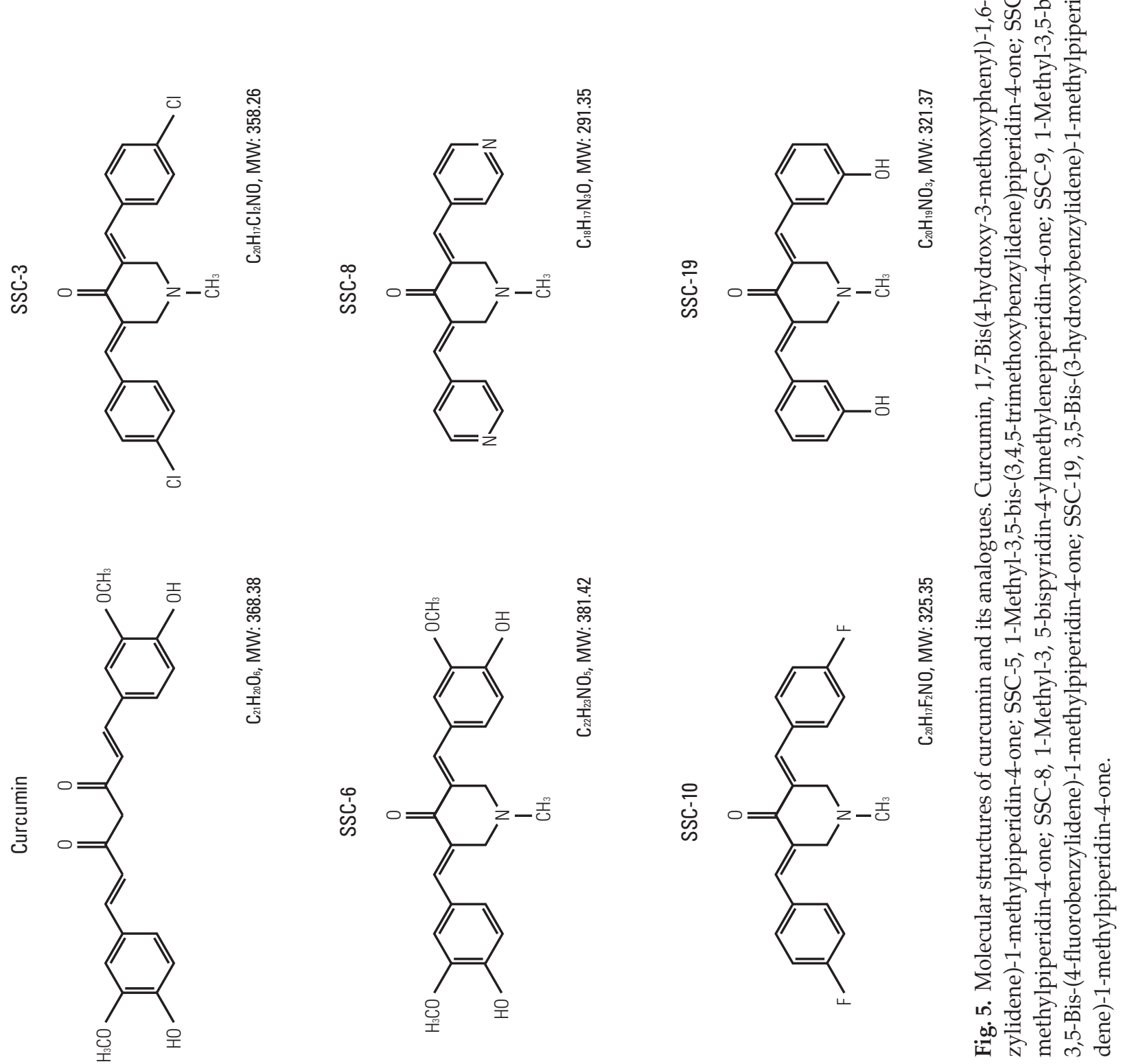

空

\section{}




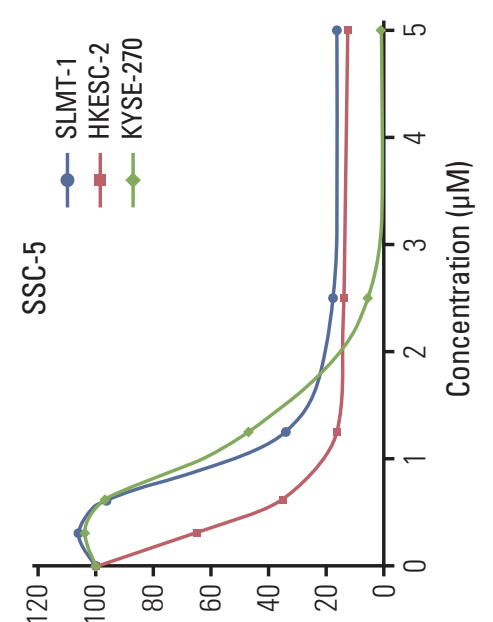

(\%) ॥әэ ә әфщ!

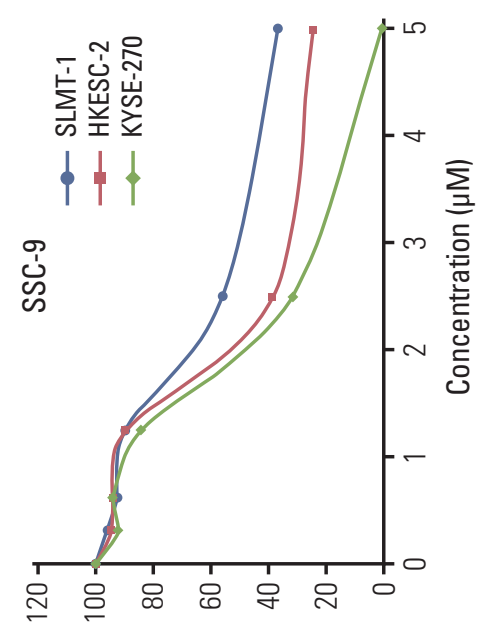

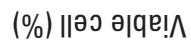

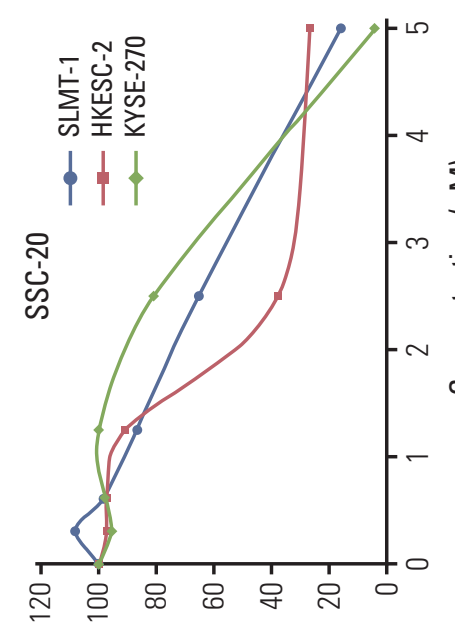

(\%) ॥әว ә әч! $\Lambda$

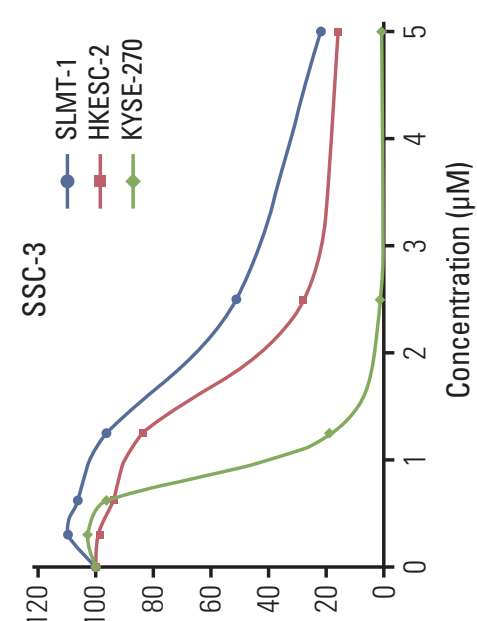

(\%) ॥әว ә әщ!

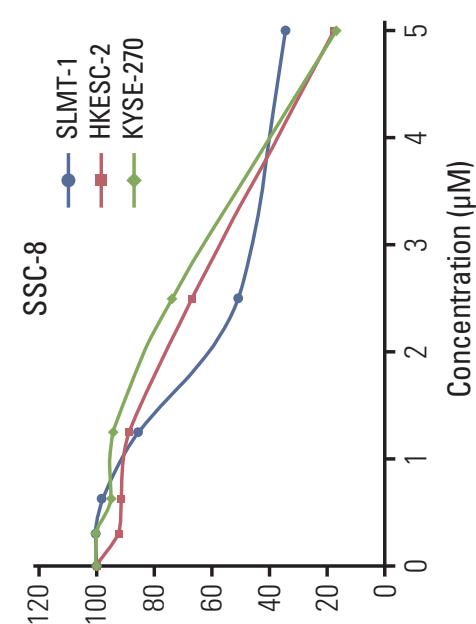

(\%) ॥әว ә वщ!
(\%) ॥әэ ә әр! $\Lambda$

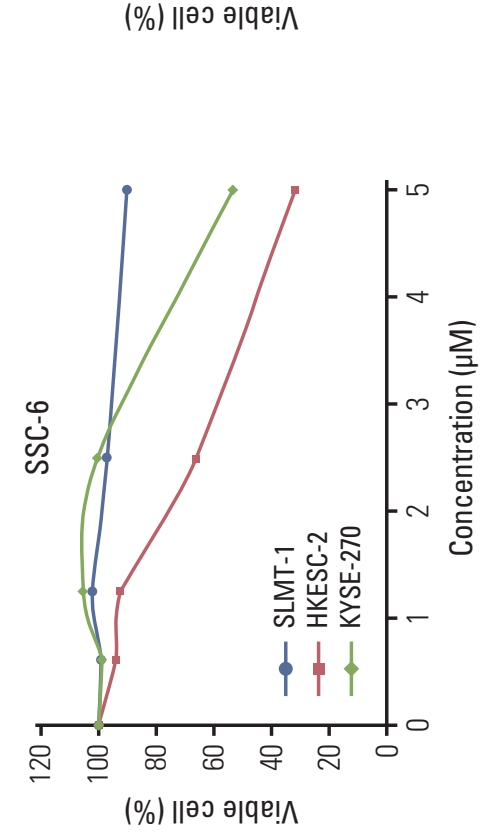

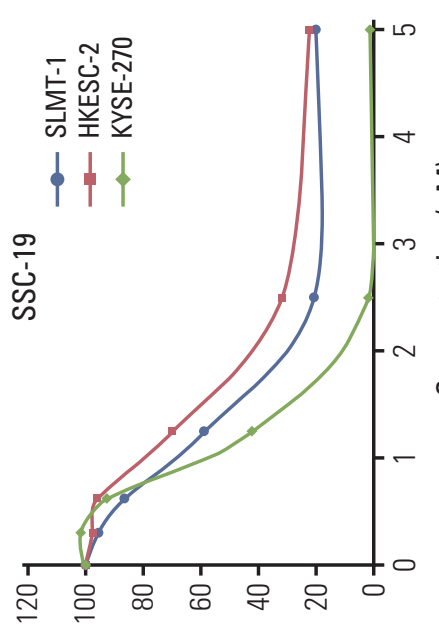

(\%) ॥әว ә әщ!

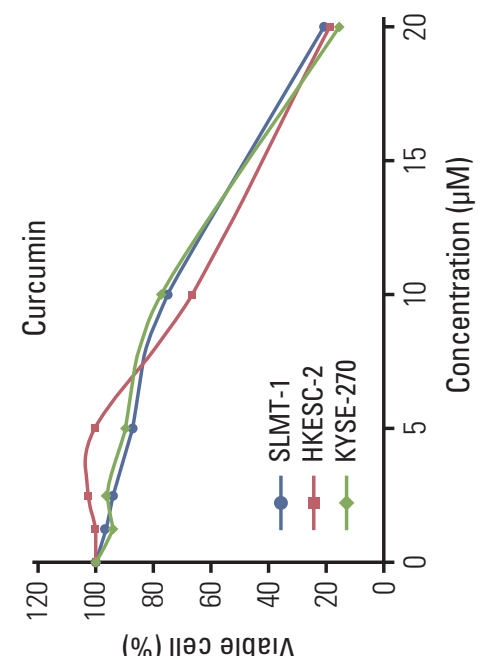

(\%) ॥әว ә әщ!
๙

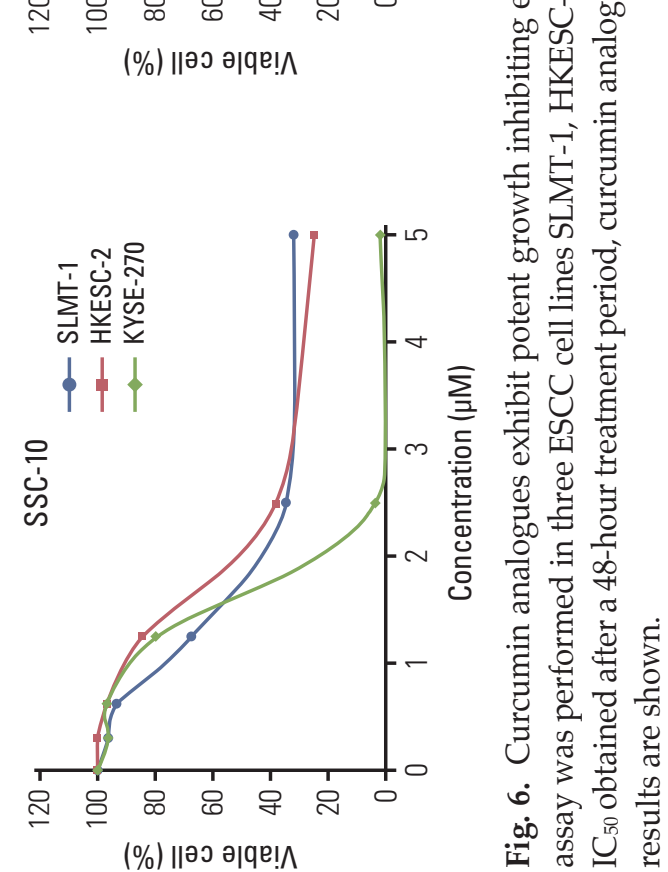


Table 1. In vitro anti-tumor effect of curcumin and its analogues against SLMT-1, HKESC-2, and KYSE-270 ESCC cell lines

\begin{tabular}{lcrr} 
& & \multicolumn{2}{c}{ IC $_{50}(\mu \mathrm{M})$} \\
\cline { 2 - 4 } Curcumin & SLMT-1 & HKESC-2 & KYSE-270 \\
SSC-3 & $14.25 \pm 0.36$ & $13.15 \pm 0.49$ & $14.43 \pm 0.11$ \\
SSC-5 & $2.75 \pm 0.44$ & $1.75 \pm 0.05$ & $0.96 \pm 0.04$ \\
SSC-6 & $1.22 \pm 0.41$ & $0.47 \pm 0.06$ & $1.21 \pm 0.18$ \\
SSC-8 & $>5$ & $2.57 \pm 1.07$ & $4.52 \pm 0.91$ \\
SSC-9 & $2.98 \pm 1.18$ & $2.33 \pm 1.04$ & $2.98 \pm 0.81$ \\
SSC-10 & $3.13 \pm 0.59$ & $1.82 \pm 0.16$ & $1.86 \pm 0.29$ \\
SSC-19 & $2.39 \pm 1.13$ & $1.82 \pm 0.16$ & $1.61 \pm 0.18$ \\
SSC-20 & $1.53 \pm 0.43$ & $1.18 \pm 0.55$ & $1.24 \pm 0.12$ \\
\hline
\end{tabular}

ESCC, esophageal squamous cell carcinoma.

Table 2. In vitro anti-tumor effect of curcumin, SSC-5 and SSC-19 against HKESC-1, KYSE-150, KYSE-180, KYSE-410, and KYSE-450 ESCC cell lines

\begin{tabular}{lrrrrr} 
& \multicolumn{3}{c}{$\mathrm{IC}_{50}(\mu \mathrm{M})$} \\
\cline { 2 - 6 } & HKESC-1 & KYSE-150 & KYSE-180 & KYSE-410 & KYSE-450 \\
Curcumin & $13.47 \pm 1.45$ & $15.83 \pm 3.62$ & $>20$ & $17.67 \pm 1.89$ & $17.37 \pm 1.60$ \\
SSC-5 & $1.29 \pm 0.52$ & $0.59 \pm 0.16$ & $0.62 \pm 0.16$ & $0.38 \pm 0.08$ & $0.69 \pm 0.09$ \\
SSC-19 & $1.08 \pm 0.07$ & $0.43 \pm 0.11$ & $0.89 \pm 0.06$ & $1.40 \pm 0.66$ & $0.55 \pm 0.11$ \\
\hline
\end{tabular}

ESCC, esophageal squamous cell carcinoma.

\section{In vitro anti-tumor effects of curcumin analogues in ESCC}

To examine whether structural modifications of curcumin could enhance its anti-tumor effects in ESCC, we synthesized eight curcumin analogues (SSC-3, SSC-5, SSC-6, SSC-8, SSC9, SSC-10, SSC-19, and SSC-20) (Fig. 5) and compared their anti-tumor effects with parental compound on SLMT-1, HKESC-2, and KYSE-270 ESCC cells in vitro. All examined curcumin analogues showed a better anti-tumor effect than the parental compound in an MTT cell proliferation assay, while curcumin exhibited a similar effect on all studied cell lines ( $\mathrm{IC}_{50}$ from $13.15 \pm 0.49$ to $14.43 \pm 0.11 \mu \mathrm{M}$ ) (Table 1, Fig. 6). Among the eight analogues, SSC-5 elicited the best antitumor effect, such that more than 10 -fold reduction in the $\mathrm{IC}_{50}$ was detected compared to curcumin (SLMT-1, 11.68fold; HKESC-2, 27.98-fold; KYSE-270, 11.93-fold) (Table 1). Second to SSC-5, SSC-19 also showed a strong anti-tumor effect, which resulted in a reduction of the $\mathrm{IC}_{50}$ by 9.31 -fold in SLMT-1, 11.14-fold in HKESC-2, and 11.64-fold in KYSE270 compared to curcumin (Table 1). To consolidate the above finding, SSC-5 and SSC-19 were subjected to a second round of MTT cell proliferation assay in an additional panel of ESCC cell lines (HKESC-1, KYSE-150, KYSE-180, KYSE410, and KYSE-450). Similar to the above result, a strong antitumor effect of these two analogues was largely maintained in this additional experiment (Table 2).

Next, we looked into two known tumor-related mechanisms, i.e., apoptosis and cell cycle arrest, and examined whether they could be affected in ESCC under the treatment of SSC-5 and SSC-19. In SLMT-1 and KYSE-450 cells treated with SSC-5 and SSC-19, an induction of apoptosis as indicated by an increase in the percentage of cells in the sub-G1 phase, as well as a cell cycle arrest at the G2/M phase were demonstrated using flow cytometry (Fig. 7A). This effect on apoptosis was further confirmed using Western blotting experiment on apoptosis-related molecules, which showed an increase of cleaved PARP and Bcl-2 de-phosphorylation in cells treated with these two curcumin analogues (Fig. 7B). On the contrary, no similar effects were observed in parallel experiments when cells were treated with the same amount of curcumin (Fig. 7). 
SLMT-1

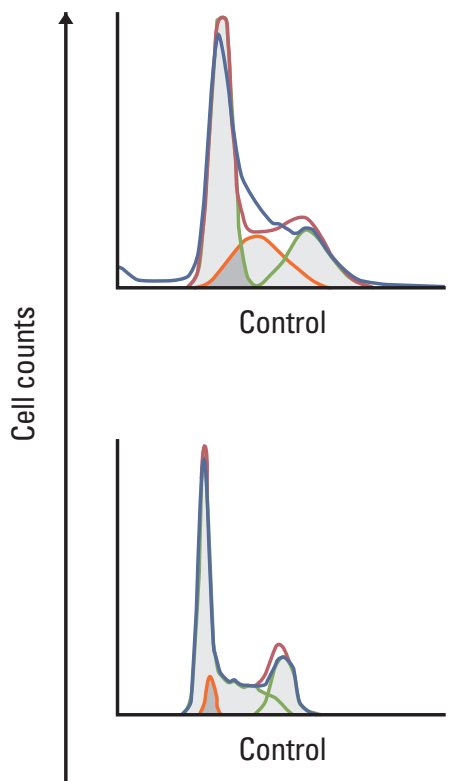

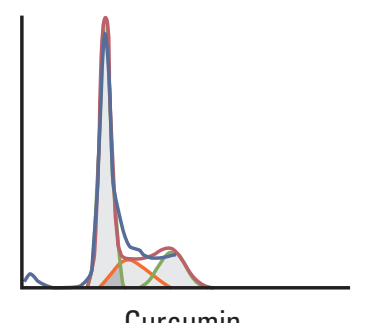

Curcumin

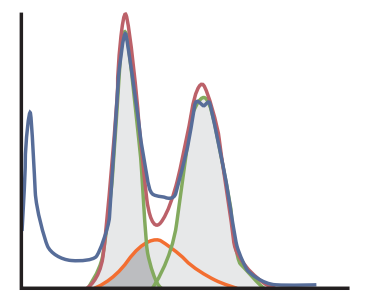

SSC-5

KYSE-450

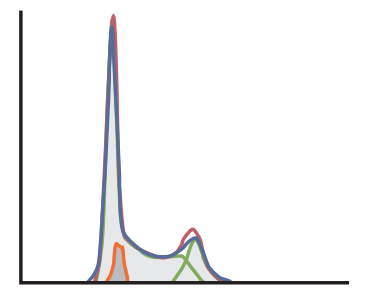

Curcumin

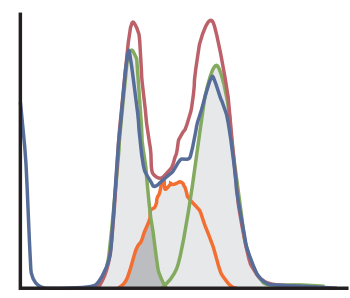

SSC-5

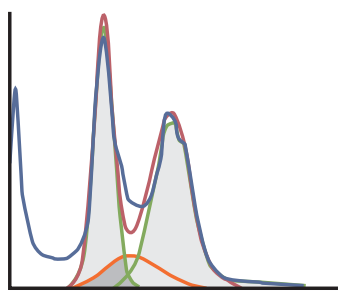

SSC-19

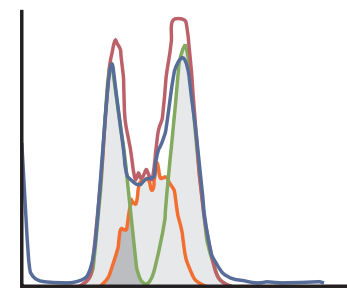

SSC-19

Propidium iodide staining
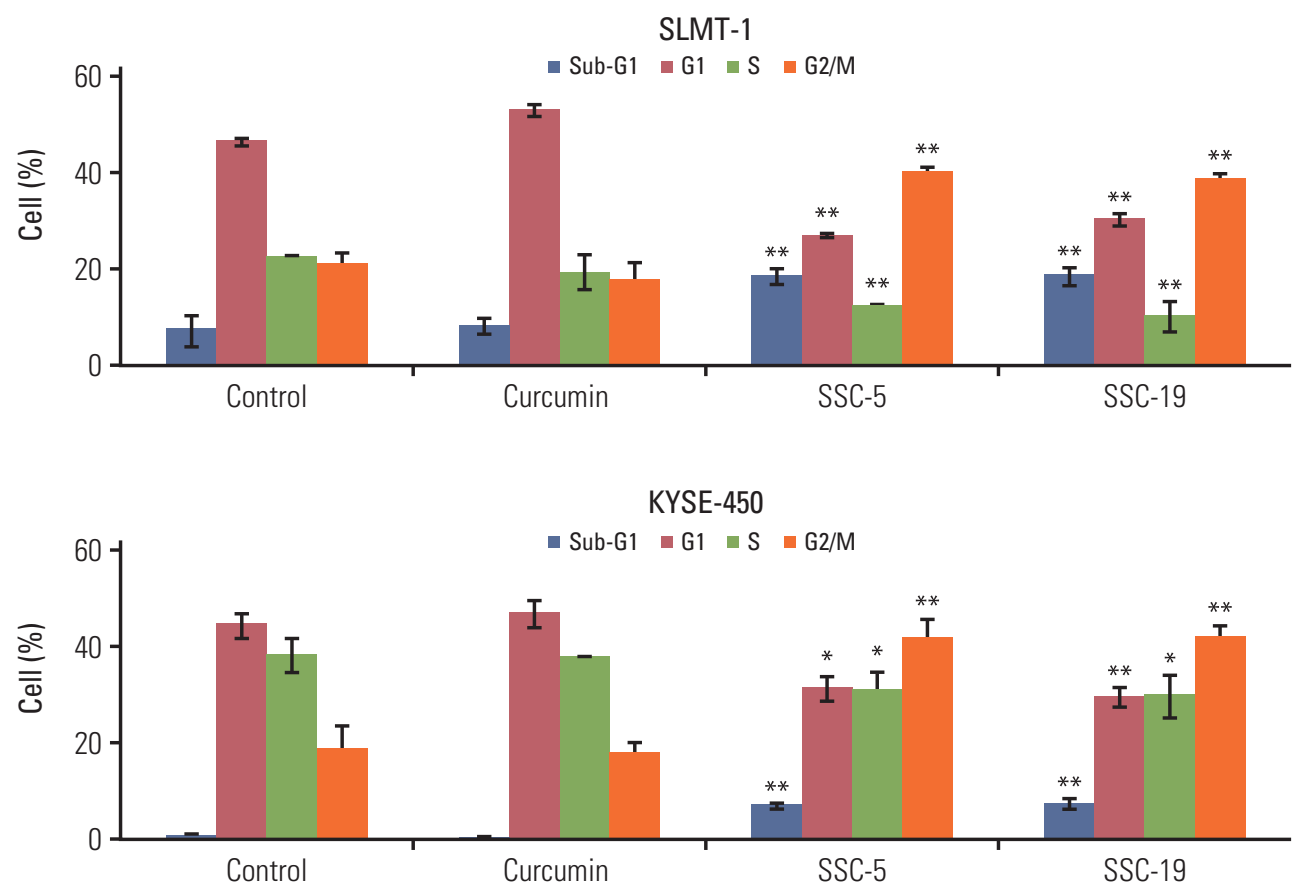

Fig. 7. SSC-5 and SSC-19 induce cell cycle arrest and apoptosis in cultured esophageal squamous cell carcinoma (ESCC) cells. (A) Flow cytometry analysis revealed the DNA content of SLMT-1 and KYSE-450 ESCC cells after treatment with dissolved in dimethyl sulfoxide (control), curcumin, SSC-5, and SSC-19. Representative flow cytometric profiles are shown. Treatment with SSC-5 and SSC-19 resulted in a significant induction of cells in the sub-G1 and G2/M phase of the cell cycle. Bars indicate mean \pm standard deviation. ${ }^{*} \mathrm{p}<0.05,{ }^{* *} \mathrm{p}<0.01$. (Continued to the next page) 

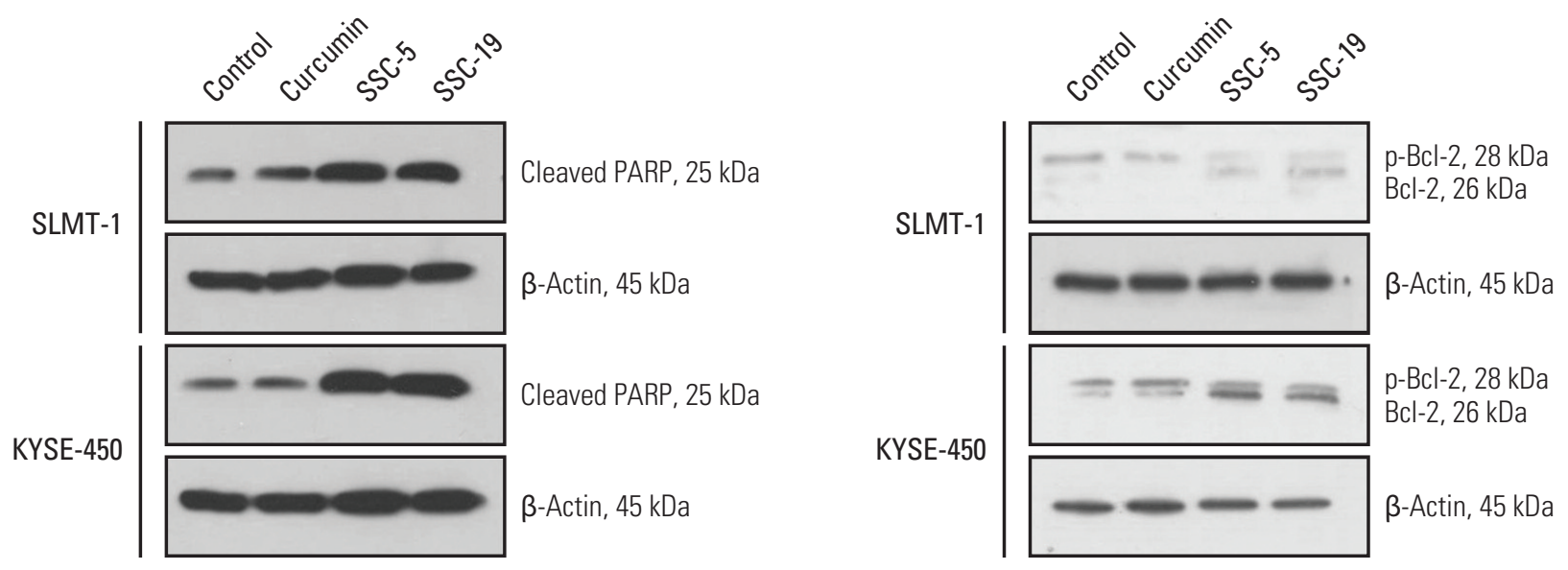

Fig. 7. (Continued from the previous page) (B) Western blotting experiment showed an obvious induction of cleaved poly(ADPribose) polymerase (PARP) and a de-phosphorylation of Bcl-2 in ESCC cells after treatment with SSC-5 and SSC-19. $\beta$-Actin was used as a loading control.

\section{Tumor growth and invasion inhibition capacity of SSC- 5 in ESCC in vivo}

To consolidate the above in vitro findings, we further examined the anti-tumor effect of SSC-5, which elicited the best anti-tumor effect among the eight curcumin analogues examined, in vivo. We observed a mild tumor size reduction in mice bearing tumor xenograft at the cervical esophagus after treatment with curcumin, which inhibited tumor growth by $57.8 \%$ in SLMT-1 (from $47.90 \pm 17.28$ to $20.21 \pm 7.57$ $\mathrm{mm}^{3}, \mathrm{p}=0.073$ ) and $47.6 \%$ in KYSE-450 (from $50.44 \pm 13.90$ to $26.45 \pm 15.94 \mathrm{~mm}^{3}, \mathrm{p}=0.154$ ). Treatment with SSC -5 associated with a more significant tumor growth inhibition compared to curcumin, and further decreased the tumor size by as much as $76.5 \%$ in SLMT-1 (from $47.90 \pm 17.28$ to $11.26 \pm 5.34$ $\mathrm{mm}^{3}, \mathrm{p}=0.030$ ) and $75.6 \%$ in KYSE-450 (from $50.44 \pm 13.90$ to $12.30 \pm 8.67 \mathrm{~mm}^{3}, \mathrm{p}=0.022$ ) (Fig. $8 \mathrm{~A}$ ).

Apart from tumor size reduction, SSC-5 treatment also lowered the risk of tumor invasion into the esophageal lumen in mice bearing tumor xenograft at the cervical esophagus. This event can be detected by examining the serial cross sections of the mouse esophagus under a microscope (Fig. 8B). In our current models on two ESCC cell lines, we found that $71.43 \%$ (SLMT-1) and $41.67 \%$ (KYSE-450) of mice presented with tumor invasion into the esophageal lumen. In SLMT-1 model, we found that SSC-5 treatment reduced the percentage of mice with tumor invasion into the esophageal lumen (from $71.43 \%$ to $28.57 \%$ ), while curcumin treatment only led to a mild reduction (from $71.43 \%$ to $60.00 \%$ ). In KYSE-450 model, however, we observed a similar reduction in both treatments with SSC-5 and curcumin. Similar to the in vitro finding, SSC-5 treatment also led to an increase of cleaved PARP in tumor xenografts when compared to curcumin and control experiment group (Fig. 9). Taken together, our data have supported the potential use of SSC-5 as a new anti-tumor compound in ESCC.

\section{Discussion}

Tumor xenograft models are commonly used in cancer research. Among different types, subcutaneous tumor xenograft model that establishes subcutaneous tumors in immunodeficient animals is widely used in cancer research for decades. Although the use of this model associates with several technical advantages, it has a limited use to study tumorstromal interaction. In view of this limitation, orthotopic tumor xenograft model that establishes tumor xenograft at the organ of origin in immunodeficient animals has been developed. Over the past years, this latter model provides a clinically relevant research platform for the study of various cancers, including esophageal, colon, and kidney [1,4,5,26,27]. Tumor microenvironment is an important factor determining treatment sensitivity, as reflected in a colon cancer study that showed differences on chemotherapeutic drug sensitivity between subcutaneous tumor xenograft and orthotopic tumor xenograft derived from the use of the same cell line $[1,28]$. In addition to treatment responses mechanisms, 
SLMT-1

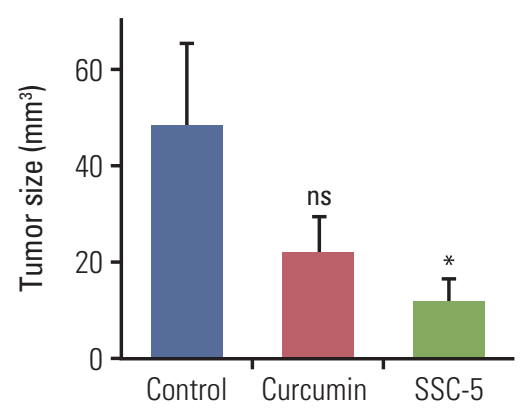

KYSE-450

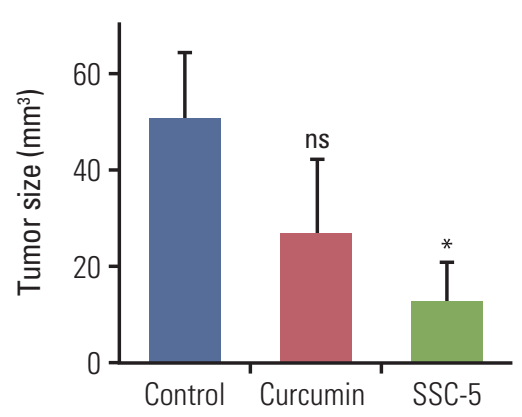

SLMT-1

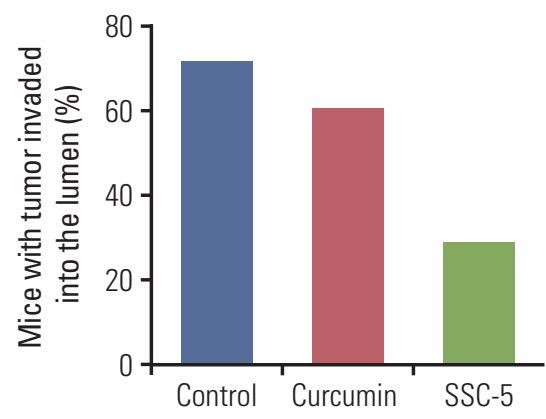

KYSE-450

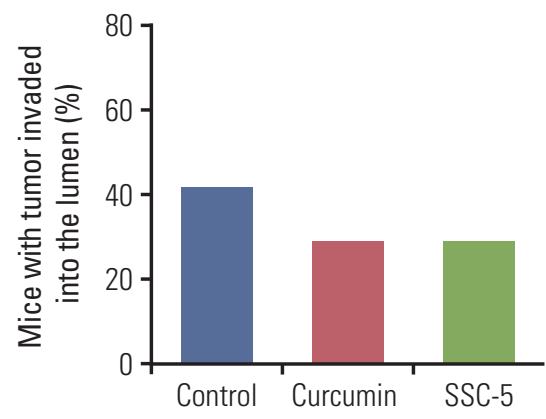

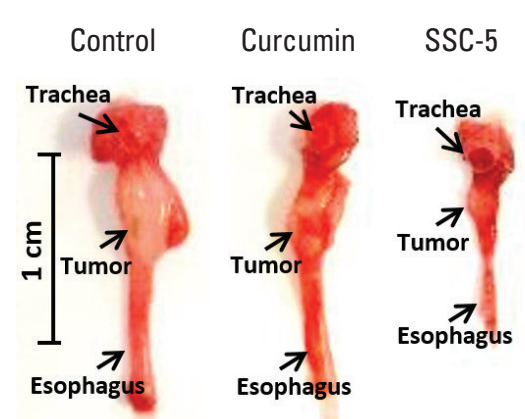

Control

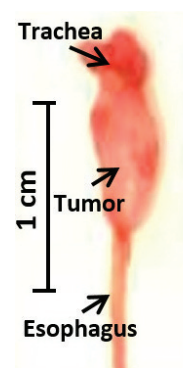

SLMT-1

KYSE-450

A

Curcumin

SSC-5

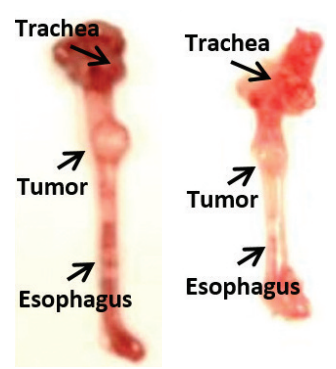

KYSE-450

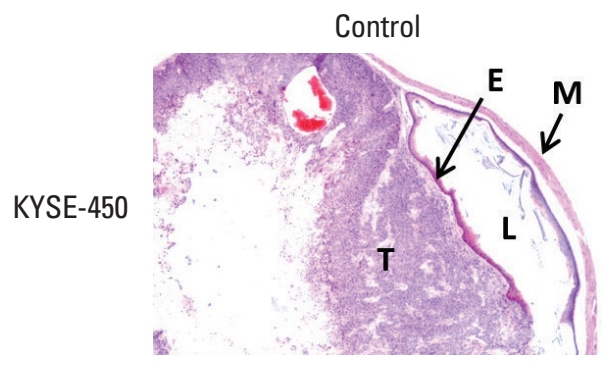

Curcumin

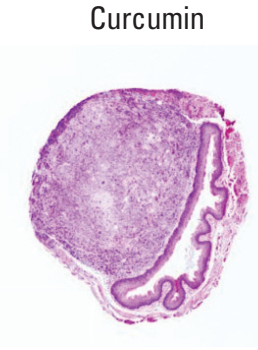

B

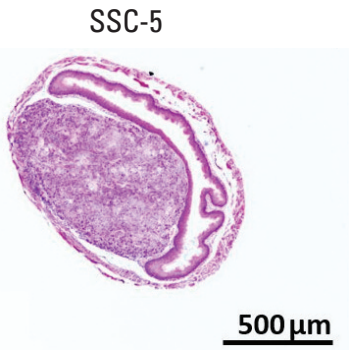

Fig. 8. SSC-5 inhibits growth and invasion abilities of orthotopic tumor xenografts. Tumor xenografts were established at the cervical esophagus in nude mice using SLMT- 1 and KYSE-450 esophageal squamous cell carcinoma (ESCC) cells. Tumorbearing mice were randomly divided into three groups for a 2-week treatment with dissolved in dimethyl sulfoxide (control), curcumin and SSC-5. (A) Treatment with SSC-5 resulted in a significant tumor size reduction (left panel) and a drop in the percentage of mice with tumor invasion into the esophageal lumen (middle panel). Right panel shows the representative photographs from each experimental group. Data are presented in mean \pm standard error of mean. ns, statistically not significant. ${ }^{*} \mathrm{p}<0.05$. (B) Representative histological images show tumor invasion into the esophageal lumen in control group, while the occurrence of such event was reduced under the treatment with curcumin or SSC-5 (×40). E, epithelium of esophagus; L, esophageal lumen; M, muscular layer of esophagus; T, tumor. 

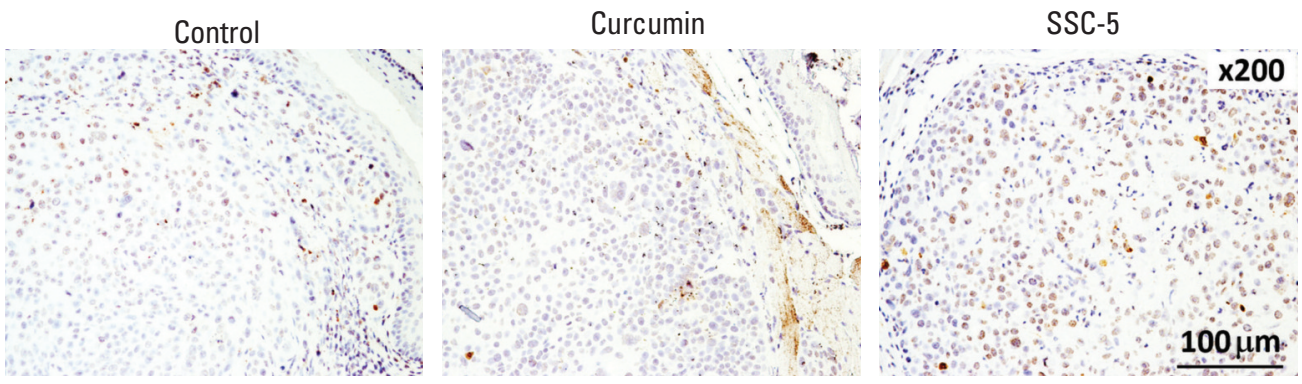

Fig. 9. SSC-5 treatment induces expression level of cleaved poly(ADP-ribose) polymerase (PARP) in orthotopic tumor xenografts. KYSE-450 esophageal squamous cell carcinoma cells were used to establish tumor xenografts at the cervical esophagus in nude mice. Treatment of these mice with SSC-5 induced the expression level of cleaved PARP in tumor xenografts, while a lower level was detected in tumor xenografts from curcumin treatment and control group.

orthotopic tumor xenograft model can also allow the study of tumor invasion in the respective tumor microenvironment $[1,29,30]$. In this study, we have provided evidences supporting the use of our developed models for preclinical ESCC research.

Different research groups have developed their own method to form tumor xenograft at different parts of the esophagus, i.e., at the cervical esophagus [4,5] or at the abdominal part [6-9]. Although both methods have been widely used, the method on cervical esophagus seems to be more clinically relevant since most ESCC originates at this site in the patients. In this study, the mice bearing tumor xenograft at this site present similar clinical features as in the patients, such as body weight loss and poor survival that could be possibly explained due to the reduced food intake or suffocation resulting from the pressures developed from the growing tumor on the esophagus and trachea. Based on these findings, we have chosen this method for further use in this study. Our method differs from two other similar methods in terms of cost, tumor location, and consistency in the tumor implantation site. The method by Hori et al. [4] involves the use of nude rats, which is more costly than the use of nude mice as in our study. Besides, their study performs tumor implantation procedure by suturing onto the esophageal wall, at which this location does not represent the tumor location in the clinical situation, while our study injects tumor cells directly into the esophageal wall. In another study, the method adopted by Ohara et al. [5] might show certain level of inconsistency in the tumor implantation site as the cells are injected through the mouse esophagus, while our method is more precise in this aspects by performing small animal surgery. Another distinct feature of our model is the use of Matrigel to prepare tumor cell suspension for injection into the esophageal wall. Our Matrigel-based method limits the initial tumor spread at the injection site, facilitating the formation of a solid tumor. Indeed, Matrigel has been widely used in other studies that develop tumor xenografts at the esophagus or at other body sites, e.g., pancreas $[6,30,31]$.

Curcumin has long been used to prevent and treat malignant diseases. Its anti-tumor effects are mediated by different molecules and pathways, such as calcium homeostasis disruption [14], nuclear factor $\kappa \mathrm{B}$ signaling inhibition [13], and DNA methylation modulation [15]. However, its clinical application is hindered by its limited potency [16]. In ESCC, a preclinical study has revealed a mild effect of curcumin on tumor growth inhibition [32], which is similar to the current study. Despite the limited anti-tumor effects, curcumin indeed provides a flexible backbone for analogues synthesis, for which some of them are proven to have promising growth inhibiting effects on cancer cells [23,24,33,34]. Based on these earlier studies, we have designed and synthesized a series of curcumin analogues and to examine their antitumor effects in ESCC. Among the studied analogues, SSC5 demonstrates strongest anti-tumor effects in cultured ESCC cells through its influences on apoptosis and cell cycle. Based on chemical structure analysis, the potent effects of SSC-5 could be partly due to its structural similarity with some known compounds with proven anti-tumor activity, e.g., 3,5bis-(3,4,5-trimethoxybenzylidene) tetrahydropyran-4-one; 3,5-bis-(3,4,5-trimethoxybenzylidene) tetrahydrothiopyran4-one; and 1-methyl-3,5-bis-(3,4,5-trimethoxybenzylidene) piperi-din-4-one $[12,22]$. Second to SSC-5, SSC-19 also demonstrates strong anti-tumor effects in ESCC cells. However, addition of hydroxyl on 2-position of phenyl ring on SSC-19 as in SSC-20 reduces the anti-tumor activity, which clearly suggests the harmful effect of this modification. In addition to the in vitro study, we have provided further evidences in an in vivo setting by showing the effect of SSC-5 on tumor invasion inhibition by stimulating apoptosis. As tumor invasion is an important process leading to tumor metastasis in advanced disease condition, the ability of SSC- 
5 on tumor invasion inhibition envisions its potential therapeutic use in ESCC.

\section{Conflicts of Interest}

Conflict of interest relevant to this article was not reported.

\section{Acknowledgments}

We would like to express our sincere thanks to Dr Anthony Lo for his comments on histological analyses. This study was supported by Theme-based Research Scheme (T42-103/16-N) of the Research Grants Council, Hong Kong. Flow cytometry data were acquired using equipment maintained by The University of Hong Kong Li Ka Shing Faculty of Medicine Faculty Core Facility.

\section{Author Details}

${ }^{1}$ Department of Surgery, The University of Hong Kong, Hong Kong, ${ }^{2}$ Collaborative Innovation Center for Diagnosis and Treatment of Infectious Diseases, Zhejiang University, Hangzhou, ${ }^{3}$ School of Chemical Engineering and Technology, Sun Yat-Sen University, Guangzhou, ${ }^{4}$ Guangdong Petrochemical Research Institute, Guangzhou, ${ }^{5}$ Guangxi Teachers Education University, College of Chemistry and Materials Science, Nanning, China

\section{References}

1. Killion JJ, Radinsky R, Fidler IJ. Orthotopic models are necessary to predict therapy of transplantable tumors in mice. Cancer Metastasis Rev. 1998;17:279-84.

2. Fidler IJ, Wilmanns C, Staroselsky A, Radinsky R, Dong Z, Fan D. Modulation of tumor cell response to chemotherapy by the organ environment. Cancer Metastasis Rev. 1994;13:209-22.

3. Dong Z, Radinsky R, Fan D, Tsan R, Bucana CD, Wilmanns C, et al. Organ-specific modulation of steady-state mdr gene expression and drug resistance in murine colon cancer cells. J Natl Cancer Inst. 1994;86:913-20.

4. Hori T, Yamashita Y, Ohira M, Matsumura Y, Muguruma K, Hirakawa K. A novel orthotopic implantation model of human esophageal carcinoma in nude rats: $\mathrm{CD} 44 \mathrm{H}$ mediates cancer cell invasion in vitro and in vivo. Int J Cancer. 2001;92: 489-96.

5. Ohara T, Takaoka M, Sakurama K, Nagaishi K, Takeda H, Shirakawa $Y$, et al. The establishment of a new mouse model with orthotopic esophageal cancer showing the esophageal stricture. Cancer Lett. 2010;293:207-12.

6. Kuroda S, Kubota T, Aoyama K, Kikuchi S, Tazawa H, Nishizaki M, et al. Establishment of a non-invasive semi-quantitative bioluminescent imaging method for monitoring of an orthotopic esophageal cancer mouse model. PLoS One. 2014;9: e114562.

7. Song S, Chang D, Cui Y, Hu J, Gong M, Ma K, et al. New orthotopic implantation model of human esophageal squamous cell carcinoma in athymic nude mice. Thorac Cancer. 2014;5:417-24.

8. Hu T, Qi H, Li P, Zhao G, Ma Y, Hao Q, et al. Comparison of GFP-expressing imageable mouse models of human esophageal squamous cell carcinoma established in various anatomical sites. Anticancer Res. 2015;35:4655-63.

9. Ip JC, Ko JM, Yu VZ, Chan KW, Lam AK, Law S, et al. A versatile orthotopic nude mouse model for study of esophageal squamous cell carcinoma. Biomed Res Int. 2015;2015:910715.

10. Padhye S, Chavan D, Pandey S, Deshpande J, Swamy KV,
Sarkar FH. Perspectives on chemopreventive and therapeutic potential of curcumin analogs in medicinal chemistry. Mini Rev Med Chem. 2010;10:372-87.

11. Bandyopadhyay D. Farmer to pharmacist: curcumin as an anti-invasive and antimetastatic agent for the treatment of cancer. Front Chem. 2014;2:113.

12. Wei X, Du ZY, Cui XX, Verano M, Mo RQ, Tang ZK, et al. Effects of cyclohexanone analogues of curcumin on growth, apoptosis and NF-kappaB activity in PC-3 human prostate cancer cells. Oncol Lett. 2012;4:279-84.

13. Kunnumakkara AB, Guha S, Krishnan S, Diagaradjane P, Gelovani J, Aggarwal BB. Curcumin potentiates antitumor activity of gemcitabine in an orthotopic model of pancreatic cancer through suppression of proliferation, angiogenesis, and inhibition of nuclear factor-kappaB-regulated gene products. Cancer Res. 2007;67:3853-61.

14. Seo JA, Kim B, Dhanasekaran DN, Tsang BK, Song YS. Curcumin induces apoptosis by inhibiting sarco/endoplasmic reticulum Ca2+ ATPase activity in ovarian cancer cells. Cancer Lett. 2016;371:30-7.

15. Liu Z, Xie Z, Jones W, Pavlovicz RE, Liu S, Yu J, et al. Curcumin is a potent DNA hypomethylation agent. Bioorg Med Chem Lett. 2009;19:706-9.

16. Nagaraju GP, Zhu S, Wen J, Farris AB, Adsay VN, Diaz R, et al. Novel synthetic curcumin analogues EF31 and UBS109 are potent DNA hypomethylating agents in pancreatic cancer. Cancer Lett. 2013;341:195-203.

17. Meiyanto E, Putri DD, Susidarti RA, Murwanti R, Sardjiman, Fitriasari A, et al. Curcumin and its analogues (PGV-0 and PGV-1) enhance sensitivity of resistant MCF-7 cells to doxorubicin through inhibition of HER2 and NF-kB activation. Asian Pac J Cancer Prev. 2014;15:179-84.

18. Lai KK, Chan KT, Choi MY, Wang HK, Fung EY, Lam HY, et al. 14-3-3sigma confers cisplatin resistance in esophageal squamous cell carcinoma cells via regulating DNA repair molecules. Tumour Biol. 2016;37:2127-36. 
19. Lee NP, Chan KT, Choi MY, Lam HY, Tung LN, Tzang FC, et al. Oxygen carrier YQ23 can enhance the chemotherapeutic drug responses of chemoresistant esophageal tumor xenografts. Cancer Chemother Pharmacol. 2015;76:1199-207.

20. Costi R, Di Santo R, Artico M, Miele G, Valentini P, Novellino $\mathrm{E}$, et al. Cinnamoyl compounds as simple molecules that inhibit p300 histone acetyltransferase. J Med Chem. 2007;50: 1973-7.

21. Wei X, Du ZY, Zheng X, Cui XX, Conney AH, Zhang K. Synthesis and evaluation of curcumin-related compounds for anticancer activity. Eur J Med Chem. 2012;53:235-45.

22. Yadav B, Taurin S, Rosengren RJ, Schumacher M, Diederich M, Somers-Edgar TJ, et al. Synthesis and cytotoxic potential of heterocyclic cyclohexanone analogues of curcumin. Bioorg Med Chem. 2010;18:6701-7.

23. Bazzaro M, Anchoori RK, Mudiam MK, Issaenko O, Kumar S, Karanam B, et al. $\alpha, \beta$-Unsaturated carbonyl system of chalcone-based derivatives is responsible for broad inhibition of proteasomal activity and preferential killing of human papilloma virus (HPV) positive cervical cancer cells. J Med Chem. 2011;54:449-56.

24. Qiu X, Liu Z, Shao WY, Liu X, Jing DP, Yu YJ, et al. Synthesis and evaluation of curcumin analogues as potential thioredoxin reductase inhibitors. Bioorg Med Chem. 2008;16:8035-41.

25. Chan KT, Choi MY, Lai KK, Tan W, Tung LN, Lam HY, et al. Overexpression of transferrin receptor CD71 and its tumorigenic properties in esophageal squamous cell carcinoma. Oncol Rep. 2014;31:1296-304.

26. Zhang L, Zhang X, Barrisford GW, Olumi AF. Lexatumumab (TRAIL-receptor $2 \mathrm{mAb}$ ) induces expression of DR5 and promotes apoptosis in primary and metastatic renal cell carcinoma in a mouse orthotopic model. Cancer Lett. 2007;251: $146-57$.

27. Abou-Elkacem L, Arns S, Brix G, Gremse F, Zopf D, Kiessling
F, et al. Regorafenib inhibits growth, angiogenesis, and metastasis in a highly aggressive, orthotopic colon cancer model. Mol Cancer Ther. 2013;12:1322-31.

28. Wilmanns C, Fan D, Obrian C, Radinsky R, Bucana C, Tsan R, et al. Modulation of doxorubicin sensitivity and level of p-glycoprotein expression in human colon-carcinoma cells by ectopic and orthotopic environments in nude-mice. Int J Oncol. 1993;3:413-22.

29. Kuo TH, Kubota T, Watanabe M, Furukawa T, Kase S, Tanino $\mathrm{H}$, et al. Site-specific chemosensitivity of human small-cell lung carcinoma growing orthotopically compared to subcutaneously in SCID mice: the importance of orthotopic models to obtain relevant drug evaluation data. Anticancer Res. 1993;13: 627-30.

30. Jiang YJ, Lee CL, Wang Q, Zhou ZW, Yang F, Jin C, et al. Establishment of an orthotopic pancreatic cancer mouse model: cells suspended and injected in Matrigel. World J Gastroenterol. 2014;20:9476-85.

31. Quatromoni JG, Predina JD, Bhojnagarwala P, Judy RP, Jiang J, De Jesus EM, et al. Adenoviral-based immunotherapy provides local disease control in an orthotopic murine model of esophageal cancer. J Immunother. 2014;37:283-92.

32. Tian F, Zhang C, Tian W, Jiang Y, Zhang X. Comparison of the effect of p65 siRNA and curcumin in promoting apoptosis in esophageal squamous cell carcinoma cells and in nude mice. Oncol Rep. 2012;28:232-40.

33. Qiu X, Du Y, Lou B, Zuo Y, Shao W, Huo Y, et al. Synthesis and identification of new 4-arylidene curcumin analogues as potential anticancer agents targeting nuclear factor-kappaB signaling pathway. J Med Chem. 2010;53:8260-73.

34. Zhou J, Geng G, Shi Q, Sauriol F, Wu JH. Design and synthesis of androgen receptor antagonists with bulky side chains for overcoming antiandrogen resistance. J Med Chem. 2009;52: 5546-50. 